\title{
Intravascular emboli relates to immunosuppressive tumor microenvironment and predicts prognosis in stage III colorectal cancer
}

\author{
Xiangping Song ${ }^{1,2}$, Di Xie $^{3}$, Fengbo Tan ${ }^{1}$, Yuan Zhou $^{1}$, Yuqiang $\mathrm{Li}^{1}$, Zhongyi Zhou ${ }^{1}$, Qian Pei ${ }^{1}$, \\ Haiping Pei $^{1,4}$ \\ ${ }^{1}$ Department of General Surgery, Xiangya Hospital, Central South University, Changsha, P.R. China \\ ${ }^{2}$ Department of Geriatric Surgery, Xiangya Hospital, Central South University, Changsha, P.R. China \\ ${ }^{3}$ Department of Neurology, The Third Xiangya Hospital, Central South University, Changsha, P.R. China \\ ${ }^{4}$ The National Clinical Research Center for Geriatric Disorders, Xiangya Hospital, Central South University, \\ Changsha, P.R. China
}

Correspondence to: Di Xie, Qian Pei, Haiping Pei; email: didixie0828@outlook.com, https://orcid.org/0000-0003-1489-7122; Peiqian1221@csu.edu.cn, php1966@csu.edu.cn

Keywords: intravascular emboli, colorectal cancer, tumor infiltrating lymphocyte, tumor microenvironment, prognosis

Received: January 4, $2021 \quad$ Accepted: July 21, $2021 \quad$ Published: August 26, 2021

Copyright: (C) 2021 Song et al. This is an open access article distributed under the terms of the Creative Commons Attribution License (CC BY 3.0), which permits unrestricted use, distribution, and reproduction in any medium, provided the original author and source are credited.

\section{ABSTRACT}

Background: Stage III colorectal cancer (CRC) patients experience varying degrees of prognosis even if receiving standard therapeutic regimes. Intravascular emboli (IVE), a type of vascular invasion, impacts the clinical outcome in CRC. In this study, we confirmed the role of IVE in predicting the prognosis of stage III CRC patients and characterized the tumor microenvironment (TME) of CRC with IVE.

Methods: Data from 220 consecutive patients (cohort 1) with stage III CRC undergoing radical surgery was collected retrospectively between January 2009 to December 2014. According to the presence of IVE, which was confirmed by two independent pathologists, patients were classified into two groups. Univariate and multivariate Cox regression analyses were performed to evaluate the relation of IVE presence to patients' prognosis. The association between IVE and clinicopathological factors was also analyzed. Furthermore, differentially expressed genes (DEGs) and gene set enrichment analyses (GSEA) were performed to describe features of the TME based on microarray data consisting of 6 patients. Tumor tissues from a separate cohort of 73 patients with stage III CRC (cohort 2) collected between June 2014 and December 2015 were used to analyze tumor-infiltrating lymphocyte (TIL) by immunohistochemistry (IHC) staining.

Results: IVE was observed in $126(57.3 \%)$ patients and could serve as an unfavorable independent prognostic predictor $(P<0.001)$ as well as lymph node metastasis $(P<0.05)$ and tumor location $(P<0.05)$. Additionally, patients with IVE had a higher neutrophil percentage $(P=0.002)$ and lower lymphocyte percentage $(P=0.002)$ relative to those without IVE. CRC with IVE had a significantly different profile of DEGs compared to CRC without IVE, and GSEA showed chronic inflammatory and immunosuppressive TME may promote IVE development. In cohort 2, tumors with IVE had fewer $\mathrm{CD3}^{+}$TILs in the stromal region, as well as fewer CD8 ${ }^{+}$TILs in both stromal and tumoral regions relative to those without IVE.

Conclusion: IVE, which was related closely to a chronic inflammatory and immunosuppressive TME, forecasted a worse prognosis of stage III CRC patients and may be taken into consideration when a therapeutic strategy is decided upon. 


\section{INTRODUCTION}

Cancer is a major threat to human life expectancy among noncommunicable diseases worldwide. According to the GLOBOCAN 2018 estimates of cancer incidence and mortality, colorectal cancer ranks fourth and second for incidence and mortality, respectively [1].

Hematogenous spread, or vascular invasion, of CRC is the major way to develop distant metastasis which may ultimately result in death. Vascular invasion can be classified into three types: tumor cells outside of the veins, tumor cell emboli in the lumen of veins, tumor cell destruction of vein walls [2]. The IVE was defined as a rounded mass of tumor in an endothelium-lined space either surrounded by a rim of smooth muscle or containing red blood cells referring to the second type of vascular invasion [3-5]. The invasion-metastasis cascade can be described briefly as follow: tumor cells exit their primary growth site and enter the vessels, survive in the circulation and arrest at a distant organ, followed by adaptation and survival in the foreign microenvironment of distant tissues [6]. Circulating tumor cells (CTCs) or circulating tumor-derived DNA (ctDNA) can be used to detect minimal residual disease (MRD) after surgery, monitor treatment response and predict prognosis, however, several limitations still remain [7-10].

IVE generally escapes from immune surveillance and will develop distant metastasis finally $[2,4,5,11,12]$, but the mechanism underlying IVE formation is unclear. The tumor microenvironment plays an important role in cancer development, metastasis and drug resistance [13] and may also play a role in IVE progress. The tumornode-metastasis (TNM) stage system has contributed to a great extent to directing the management and treatment of CRC. With the development of precise treatment and insights into $\mathrm{CRC}$, many more factors should be taken into consideration to optimize decisionmaking [14].

Patients who are diagnosed with early-stage CRC and receive curative treatments have a better prognosis. The five-year survival rate is $90 \%$ for patients with localized stages of CRC (there is no sign that cancer has spread outside of the colon or rectum). For patients with regional stage CRC (cancer has spread outside the colon or rectum to nearby structures or lymph nodes), the five year survival rate is $71 \%$, which is an improvement from previous decades [15]. Though patients with stage III CRC often receive radio-/chemotherapy systematically along with surgery, the clinical prognosis of stage III CRC varies a lot and metastasis is the leading cause of death. Previous studies suggest patients with IVE have a worse prognosis including CRC [2-5, $11,12]$. CRC patients with IVE should be treated as another subtype.

In our study, we evaluated the prognostic significance of IVE in patients with stage III CRC after radical surgery and profiled the DEGs and tumor microenvironment characteristics of CRC with IVE.

\section{MATERIALS AND METHODS}

\section{Patients and clinical follow-up}

Data from consecutive patients with CRC were collected in Xiangya Hospital, Hunan, China between January 2009 to December 2014. The inclusion criteria required that patients had received radical surgery (R0 excision), confirmed stage III CRC histologically according to the AJCC7th classification. The exclusion criteria included: anti-tumor therapy before surgery; colorectal cancer with intestinal perforation; vascular disorder or inflammation-related diseases; and incomplete clinicopathological data. Finally, 220 patients were included in cohort 1 . The last follow-up time was December 2017. Disease-free survival (DFS) was defined as the interval from radical surgery to recurrence or metastasis, the appearance of secondary colon or rectal cancer, or death, whichever occurred first. Overall survival (OS) was defined as the interval from radical surgery to mortality, or it was censored at the last known date alive. Similarly, 73 patients diagnosed with stage III CRC between June 2014 and December 2015 in the same institution were included in cohort 2.

For microarray analysis, six patients diagnosed with stage III CRC post-surgery were selected. Both cancer tissue and paired adjacent non-cancerous tissue were collected and stored in liquid nitrogen. Three patients were presenting with IVE and the other three were not. Four groups were defined as follows: cancer tissues with IVE (IVE group) and paired adjacent noncancerous tissue (group 1); cancer tissues without IVE (non-IVE group) and paired adjacent non-cancerous tissue (group 2).

\section{Clinicopathological data}

Blood laboratory measurements were carried out within 7 days before surgery. All patient-related data were retrieved from the medical record database, including blood count, comprehensive metabolic test, coagulation related indices, tumor markers including carcinoembryonic antigen (CEA), carbohydrate antigen 199 (CA199) and CA242, and demographic information and postoperative pathological results. The diagnostic 
criteria for IVE were described in detail previously [3]. Briefly, there was a cluster of cancer cells in blood vessel confirmed by Hematoxylin and Eosin $(\mathrm{H} \& \mathrm{E})$ or immunohistochemistry (IHC) staining [3]. A minimum of 4 paraffin tumor blocks were used to optimize detection. For each block, we examined the entire filed to make sure weather there is IVE presence or not. When we encountered difficulties in identification and distinguishing sample features from lymphatic vessel invasion (LVI) in hematoxylin and eosin (H\&E) slices, we marked the blood vessel endothelium and lymphatic vessel endothelium, with CD34 and D2-40 IHC staining, respectively (Supplementary Figure 1). The presence of IVE was confirmed by two independent pathologists.

\section{Immunohistochemistry staining and TILs assessment}

Immunohistochemistry staining was performed as previously described $[3,16]$. Briefly, the sections were dewaxed and rehydrated. Then, the sections were immersed in $10 \mathrm{mmol} / \mathrm{L}$ sodium citrate buffer $(\mathrm{pH}=6)$, boiled and allowed to cool for 20 minutes to repair the sealed antigen. The sections were then incubated in $3 \%$ hydrogen peroxide solution for 25 minutes to block endogenous catalase. After blocking with 3\% BSA, the sections were incubated with mouse monoclonal antibody against human CD8 (1:400 dilution, ab199016, Abcam) or rabbit polyclonal antibody against human CD3 (1:200 dilution, gb11137, Servicebio) overnight at $4^{\circ} \mathrm{C}$, followed by incubation with goat anti-rabbit (1:200 dilution, GB23303, Servicebio) or anti-mouse (1:200 dilution, GB23301, Servicebio) IgG H\&L (HRP) antibody (1:200 dilution, ab205718, Abcam) for 50 minutes at room temperature. The sections were stained with $0.05 \%$ diaminobenzidine tetrahydrochloride (DAB) for 5 minutes and then counterstained with hematoxylin, dehydrated, and mounted. The whole slide image was scanned by an automatic digital slide scan system (KF-PRO-400, KFBIO) and viewed through KViewer software (KFBIO). For positive cells counting, three fields $(20 \times)$ of each region (stomal, tumoral, and boundary region in the tumor area) were selected randomly and counted blindly by covering IVE status.

\section{RNA isolation and gene expression profiling}

The Agilent Human Gene Expression $(8 * 60 \mathrm{~K}$, Design ID: 039494) was used in this experiment. Total RNA was isolated from 12 frozen samples and quantified by NanoDrop ND-2000 (Thermo Scientific). RNA integrity was assessed using Agilent Bioanalyzer 2100 (Agilent Technologies). The sample labeling, microarray hybridization, and washing were performed based on the manufacturer's standard protocols. Briefly, total RNA was transcribed to double-stranded cDNA, then synthesized into cRNA and labeled with Cyanine-3CTP. The labeled cRNAs were hybridized onto the microarray plate. After washing, the arrays were scanned by the Agilent Scanner G2505C (Agilent Technologies).

Feature Extraction software (version10.7.1.1, Agilent Technologies) was used to analyze array images to get raw data. Genespring (version13.1, Agilent Technologies) was employed for basic analysis of the raw data. To begin with, the raw data was normalized using the quantile algorithm. Probes for which $100 \%$ of the values in any of all available groups flagged as "Detected" were chosen for further data analysis. The number of differentially expressed genes (DEGs) were refined via a fold change as well as $P$ value ( $t$-test) cutoff. Hierarchical clustering was performed to display the distinguishable genes' expression patterns among samples. All the analysis was performed on the $\mathrm{R}$ studio platform using packages including limma, gplots, and ggplot2.

Gene set enrichment analysis [17] was performed on GSEA software 3.0 to verify the biologic phenotype between groups. All prior gene sets were downloaded from MsigDB (Molecular Signatures Database).

The study was approved by the Ethics Review Committee of Xiangya Hospital, Central South University and performed in accordance with the Declaration of Helsinki.

\section{Statistics}

Association between IVE and clinical characteristics was assessed by Chi-square $\left(\chi^{2}\right)$ test. The $t$-test was used to analyze the differences between the means of two groups. Data are presented as mean \pm s.d. Univariate and multivariate Cox regression analyses were performed to evaluate clinical characteristics related to DFS and OS. Survival curves were made using the Kaplan-Meier method using GraphPad Prism 7.0 and compared by the log-rank test. All statistical analyses were performed using the Statistical Package for Social Sciences version 25.0 (SPSS Inc., Chicago, IL, USA). A two-sided $P<0.05$ was considered statistically significant. In GSEA, enrichment results satisfying a nominal $P$-value cutoff of 0.05 with a false discovery rate $(\mathrm{FDR}) \mathrm{q}$-value $<0.25$ were considered statistically significant.

\section{RESULTS}

\section{Patient characteristics}

Cohort 1 included 220 patients with stage III colorectal cancer. All the patients received radical surgery at the 
Department of Gastrointestinal Surgery of our hospital from January 2009 to December 2014. The mean age and age range at the time of diagnosis were 69 years old and 14 to 83 years old, respectively. The ratio of male to female was 126/94. Among all patients, 84 (38.2\%) had colon cancer and $136(61.8 \%)$ had rectal cancer. There were 161 patients received adjuvant chemotherapy after surgery, among which there were only 8 receiving radiotherapy at the same time, 136 and 17 getting FOLFOX4/6 and XELOX, respectively. Laboratory results from pre-operation blood tests, including protein levels, hepatorenal function exam, serum electrolytes, various blood cell counts and coagulation-related indices, are showed in Supplementary Table 1 . The last date of follow-up was December 2017 and the median follow-up duration was 64 months (range from 15 to 106 months). Cohort 2 included 73 patients, of which there were 30 patients with IVE.

\section{Survival analysis}

To assess the prognostic significance of some clinicopathological characteristics and IVE in patients with stage III CRC in cohort 1, univariate and multivariate analyses were applied. In univariate analysis, the results revealed that IVE, lymph node metastasis, tumor location, histologic type, obstruction, and serum CA199 levels were associated with both OS and DFS $(P<0.05)$. On the other hand, gross tumor morphology was only related to OS $(P=0.026)$ but not DFS $(P=0.078)$ (Table 1$)$. All factors mentioned above, as well as the tumor invasion depth $(P<0.1)$, were included in the multivariate analysis, which suggests IVE was statistically significant for both OS (HR: 4.486, 95\%CI: 2.638-7.631; $P<0.001$ ) and DFS (HR: $4.949,95 \%$ CI: $2.996-8.174 ; P<0.001$ ), as well as lymph node metastasis and tumor location (Table 2). Of the 220 patients, 113 developed tumor recurrence (nonIVE group, 24 versus IVE group, 89) and 103 had cancer-related deaths (non-IVE group, 21 versus IVE group, 82). Kaplan-Meier analysis and log-rank tests were applied to assess for differences in OS and DFS between groups characterized by IVE presence or not. It showed patients with IVE had a worse outcome after surgery and median OS and DFS of stage III CRC patients with IVE were 35 and 17 months, respectively. (Figure 1A, 1B).

\section{Association between IVE and clinicopathologic characteristics}

In cohort 1, IVE was observed in $126(57.3 \%)$ specimens (Figure 2A, 2B). Our analysis revealed that IVE was associated with lymph node metastasis $(P<0.001)$, tumor histologic type $(P<0.001)$ and pre-operation obstruction symptom $(P=0.008)$ (Supplementary Table 2). Importantly, patients with IVE had a higher neutrophil percentage (non-IVE group, $59.26 \pm 10.38$ versus IVE group, $63.38 \pm 10.17 ; P=0.002$ ) and lower lymphocyte percentage (non-IVE group, $28.77 \pm 9.62$ versus IVE group, $24.80 \pm 9.19 ; P=0.002$ ) (Figure 2C, $2 \mathrm{D}$ and Supplementary Table 3). Additionally, serum creatinine, a marker for renal function assessment, was higher in the IVE group $(P=0.008)$ (Supplementary Table 3$)$.

\section{Signatures of differential gene expression between groups}

A total of 12 samples from 6 patients (Supplementary Table 4) with stage III CRC were used for microarray analysis. These samples consisted of 6 fresh cancer tissues and their paired non-cancerous tissues. Compared with paired group 2, there were 1011 upregulated genes and 1080 down-regulated genes with absolute fold change $>2$ and $P<0.05$ in the non-IVE group (Figure 3A). Meanwhile, there were 1799 upregulated genes and 1807 down-regulated genes with absolute fold change $>2$ and $P<0.05$ in the IVE group compared with paired group 1 (Figure $3 \mathrm{~B}$ ). The number of DEGs in the IVE group was higher compared to the non-IVE group, however, only a small number of genes were shared by both groups (Figure 3C).

Next, the IVE group was compared with the non-IVE group. There were 670 genes with fold change $>2$ (306 up-regulated and 264 down-regulated) and 93 genes with fold change $>4$ (52 up-regulated and 41 down-regulated) compared with the non-IVE group (Figure 4A). The top ten up- and down-regulated genes were listed in Supplementary Table 5. DEGs clustering analysis was performed and it was revealed that the observed gene signatures distinguished IVE tumors from non-IVE tumors effectively (Figure 4B).

\section{CRC with IVE had a more immunosuppressive tumor microenvironment (TME)}

The results above (Figure 2 and Supplementary Table 3) suggest that inflammation and immune response may play a role in IVE development. To identify enriched genes that may be involved in immune response or inflammation, GSEA analysis was performed by using gene expression data and some prior defined gene sets. Our analysis revealed that the IVE group correlated with chronic inflammatory response positively and lymphocyte-mediated immunity negatively compared with the non-IVE group (Figure 5). Additionally, cytokine/chemokine production pathways were also analyzed between IVE and non-IVE group. Gene sets promoting the production of some interleukin (IL) 
Table 1. Univariate analysis in relation to OS and DFS.

\begin{tabular}{|c|c|c|c|c|c|c|c|}
\hline \multirow{2}{*}{ Parameters } & & \multicolumn{3}{|c|}{ OS } & \multicolumn{3}{|c|}{ DFS } \\
\hline & & $P$-value & HR & $95 \% \mathrm{CI}$ & $P$-value & HR & $95 \% \mathrm{CI}$ \\
\hline \multirow{2}{*}{ Age } & $<60$ years & & & & & & \\
\hline & $\geq 60$ years & 0.418 & 1.176 & $0.795-1.739$ & 0.887 & 1.028 & $0.705-1.498$ \\
\hline \multirow{3}{*}{ Gender } & Male & & & & & & \\
\hline & Female & 0.322 & 0.819 & $0.552-1.215$ & 0.460 & 0.868 & $0.596-1.264$ \\
\hline & Left colon & 0.020 & & & 0.007 & & \\
\hline \multirow[t]{3}{*}{ Tumor location } & Right colon & 0.636 & 1.189 & $0.580-2.437$ & 0.801 & 1.093 & $0.546-2.190$ \\
\hline & Rectum & 0.018 & 2.001 & $1.128-3.550$ & 0.012 & 2.022 & $1.164-3.512$ \\
\hline & Well/moderate & $<0.001$ & & & 0.007 & & \\
\hline \multirow[t]{3}{*}{ Histologic type } & Poor & 0.000 & 2.699 & $1.747-4.169$ & 0.002 & 1.975 & $1.292-3.018$ \\
\hline & Mucinous/mix & 0.146 & 1.546 & $0.860-2.779$ & 0.648 & 1.144 & $0.643-2.035$ \\
\hline & Ulcerative & 0.026 & & & 0.078 & & \\
\hline \multirow[t]{3}{*}{ Tumor morphology } & Infiltrating & 0.032 & 2.184 & $1.068-4.464$ & 0.089 & 1.851 & $0.911-3.758$ \\
\hline & Protruded & 0.318 & 0.809 & $0.533-1.277$ & 0.325 & 0.82 & $0.552-1.218$ \\
\hline & $<5 \mathrm{~cm}$ & & & & & & \\
\hline Tumor size & $\geq 5 \mathrm{~cm}$ & 0.501 & 0.872 & $0.584-1.301$ & 0.389 & 0.846 & $0.577-1.239$ \\
\hline \multirow{2}{*}{ Obstruction symptoms } & NO & & & & & & \\
\hline & YES & 0.002 & 2.839 & $1.469-5.487$ & 0.001 & 2.868 & $1.530-5.379$ \\
\hline \multirow{2}{*}{ Invasive depth } & $\mathrm{T} 1-2$ & & & & & & \\
\hline & T3-4 & 0.064 & 2.178 & $0.954-4.969$ & 0.060 & 2.084 & $0.970-4.480$ \\
\hline \multirow{2}{*}{ Lymph node metastasis } & $\mathrm{pN} 1$ & & & & & & \\
\hline & $\mathrm{pN} 2$ & $<0.001$ & 3.78 & $2.497-5723$ & $<0.001$ & 2.883 & $1.962-4.238$ \\
\hline \multirow{2}{*}{ CEA } & $<5 \mathrm{ng} / \mathrm{ml}$ & & & & & & \\
\hline & $\geq 5 \mathrm{ng} / \mathrm{ml}$ & 0.332 & 1.229 & $0.810-1.865$ & 0.628 & 1.105 & $0.737-1.658$ \\
\hline \multirow{2}{*}{ CA199 } & $<35 \mathrm{kU} / \mathrm{L}$ & & & & & & \\
\hline & $\geq 35 \mathrm{kU} / \mathrm{L}$ & 0.028 & 1.672 & $1.056-2.647$ & 0.039 & 1.602 & $1.025-2.505$ \\
\hline \multirow{2}{*}{ CA242 } & $<20 \mathrm{kU} / \mathrm{L}$ & & & & & & \\
\hline & $\geq 20 \mathrm{kU} / \mathrm{L}$ & 0.313 & 1.296 & $0.783-2.143$ & 0.537 & 1.17 & $0.711-1.925$ \\
\hline \multirow{2}{*}{ IVE } & NO & & & & & & \\
\hline & YES & $<0.001$ & 5.224 & $3.188-8.561$ & $<0.001$ & 5.161 & $3.250-8.198$ \\
\hline
\end{tabular}

Abbreviations: CEA, carcinoembryonic antigen; CA199, carbohydrate antigen 199; CA242, carbohydrate antigen 242; IVE, intravascular emboli.

including IL-4, IL-8, and IL-17 and negatively regulating interferon $\gamma(\mathrm{IFN} \gamma)$ production were enriched in the IVE group (Figure 5). Differential enrichment of those gene sets was not observed between the group 1 and group 2. Thus, the chronic inflammatory and immunosuppressive tumor microenvironment may promote IVE formation and CRC progression.

\section{CRC with IVE had fewer $\mathrm{CD3}^{+}$and $\mathrm{CDB}^{+}$TILs}

$\mathrm{CD}^{+}$and $\mathrm{CD} 8^{+}$subsets represent the total infiltrating $\mathrm{T}$ cells and cytotoxic $\mathrm{T}$ cells, respectively.

The density of TILs reflects the immune status in TME. We found TILs did not distribute equally in tumor areas including stromal region, tumor region, and boundary region (Figure 6). Compared to tumors without IVE, those with IVE had fewer $\mathrm{CD}^{+}$and $\mathrm{CD} 8^{+}$TILs in both stromal and tumoral regions, while fewer $\mathrm{CD}^{+}$TILs were detected in tumoral regions (Figure 6A-6C). Notably, TILs were more abundant in the stromal region compared with tumor region (Figure 6A-6C), which suggested a pivotal role for the stroma in immunemediated cancer control. TILs accumulated prominently at the frontier of the tumor (Figure 6A), however, only a small difference of $\mathrm{CD}^{+}$TILs was observed between non-IVE and IVE tumors (Figure 6D).

\section{DISCUSSION}

Except for the TNM system, molecular markers like microsatellite instability (MSI), KRAS and BRAF 
Table 2. Multivariate analysis in relation to OS and DFS.

\begin{tabular}{|c|c|c|c|c|c|c|c|}
\hline \multirow{2}{*}{ Parameters } & & \multicolumn{3}{|c|}{ OS } & \multicolumn{3}{|c|}{ DFS } \\
\hline & & $P$-value & HR & $95 \% \mathrm{CI}$ & $P$-value & HR & $95 \% \mathrm{CI}$ \\
\hline \multirow{3}{*}{ Tumor location } & Left colon & 0.112 & & & 0.015 & & \\
\hline & Right colon & 0.548 & 1.272 & $0.580-2.789$ & 0.497 & 1.303 & $0.606-2.801$ \\
\hline & Rectum & 0.050 & 1.938 & $0.999-3.760$ & 0.009 & 2.337 & $1.239-4.408$ \\
\hline \multirow{3}{*}{ Histologic type } & Well/moderate & 0.646 & & & 0.648 & & \\
\hline & Poor & 0.512 & 1.188 & $0.710-1.987$ & 0.354 & 0.791 & $0.481-1.300$ \\
\hline & Mucinous & 0.413 & 1.318 & $0.681-2.551$ & 0.910 & 0.964 & $0.506-1.835$ \\
\hline \multirow{3}{*}{ Tumor morphology } & Ulcerative & 0.305 & & & 0.401 & & \\
\hline & Infiltrating & 0.194 & 1.679 & $0.769-3.666$ & 0.253 & 1.566 & $0.726-3.379$ \\
\hline & Protruded & 0.532 & 0.86 & $0.535-1.381$ & 0.589 & 0.887 & $0.575-1.369$ \\
\hline \multirow{2}{*}{ Obstruction } & NO & & & & & & \\
\hline & YES & 0.547 & 0.125 & $0.599-2.631$ & 0.281 & 1.464 & $0.733-2.925$ \\
\hline \multirow{2}{*}{ Invasive depth } & $\mathrm{T} 1-2$ & & & & & & \\
\hline & T3-4 & 0.456 & 1.381 & $0.591-3.227$ & 0.325 & 1.481 & $0.677-3.237$ \\
\hline \multirow{2}{*}{ Lymph node metastasis } & $\mathrm{N} 1$ & & & & & & \\
\hline & N2 & 0.001 & 2.334 & $1.445-3.772$ & 0.019 & 1.697 & $1.091-2.640$ \\
\hline \multirow{2}{*}{ CA199 } & $<35 \mathrm{kU} / \mathrm{L}$ & & & & & & \\
\hline & $\geq 35 \mathrm{kU} / \mathrm{L}$ & 0.193 & 1.412 & $0.840-2.371$ & 0.105 & 1.509 & $0.917-2.483$ \\
\hline \multirow{2}{*}{ IVE } & NO & & & & & & \\
\hline & YES & $<0.001$ & 4.486 & $2.638-7.631$ & $<0.001$ & 4.949 & $2.996-8.174$ \\
\hline
\end{tabular}

mutations can predict the prognosis and direct the treatment of specific stage CRC [14, 18]. For patients with stage III CRC, the recommended treatment is radical surgery along with local radiotherapy and/or systemic chemotherapy regardless [19]. Though patients receive the same treatment, the outcome varies a lot and is largely unsatisfactory. It is necessary to identify new prognostic markers to help modify the therapeutic regimen for patients with stage III CRC.

According to the AJCC staging system [20], lymph node metastasis is the main characteristic of stage III $\mathrm{CRC}$, which indicates regional spread via lymphatic vessels. But death due to distant organ metastasis via hematogenous spread is common. Identifying the

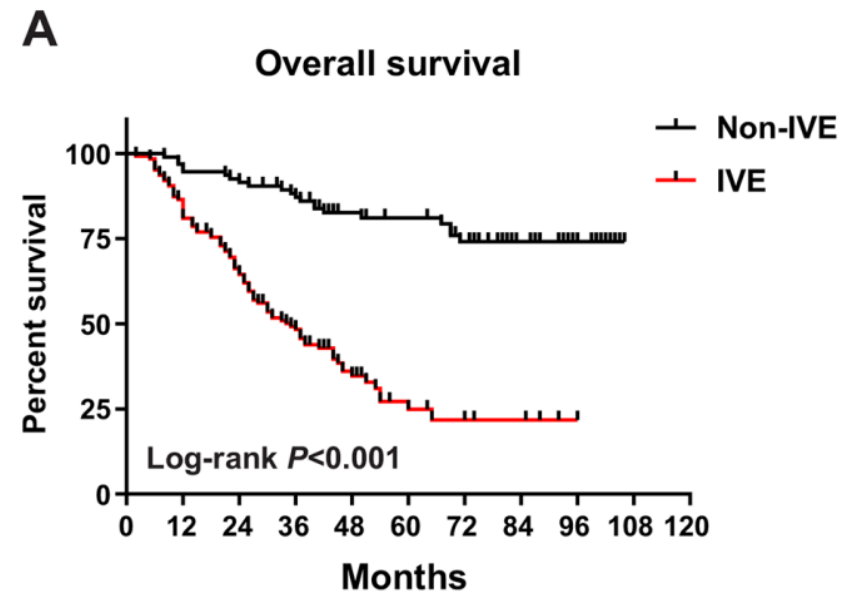

B

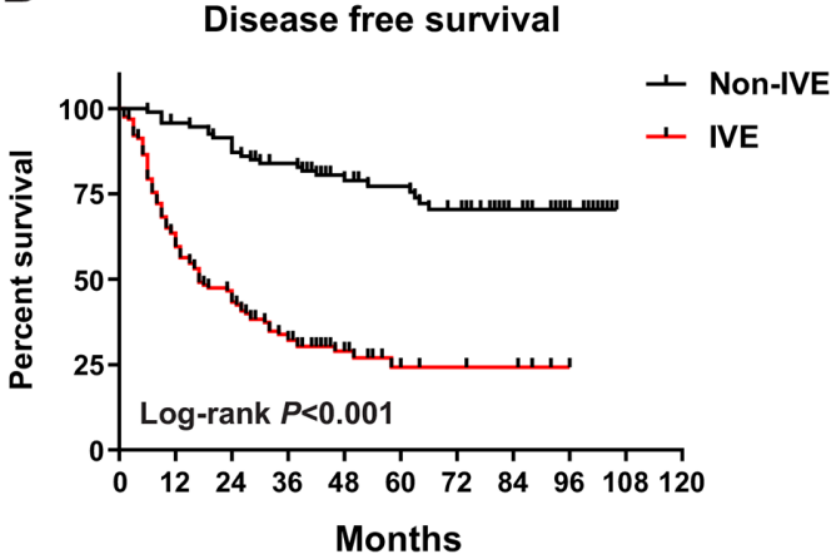

Figure 1. OS and DFS in IVE and non-IVE CRC patients. (A) IVE patients had worse OS compared with non-IVE patients; (B) IVE patients had worse DFS compared with non-IVE patients. 
metastatic process in its early stages is critical. Unlike the detection of CTCs or ctDNA, the presence of IVE indicates cluster of tumor cells have survived and will likely develop into distant metastasis. Previous studies found vascular invasion was an unfavorable prognostic factor in various solid cancers including CRC $[2,12,21$, 22]. In our study, over half of stage III CRC patients analyzed presented with IVE and had a worse prognosis, which was consistent with previous findings [3]. It has been established that patients with stage IV CRC can benefit from targeted therapy [23-25]. Given our findings outlines above and previous research, the survival time of stage III CRC patients with IVE is comparable with stage IV CRC patients. It's a question whether it is appropriate to treat those as local advanced cancer. Further clinic research is needed to find out if
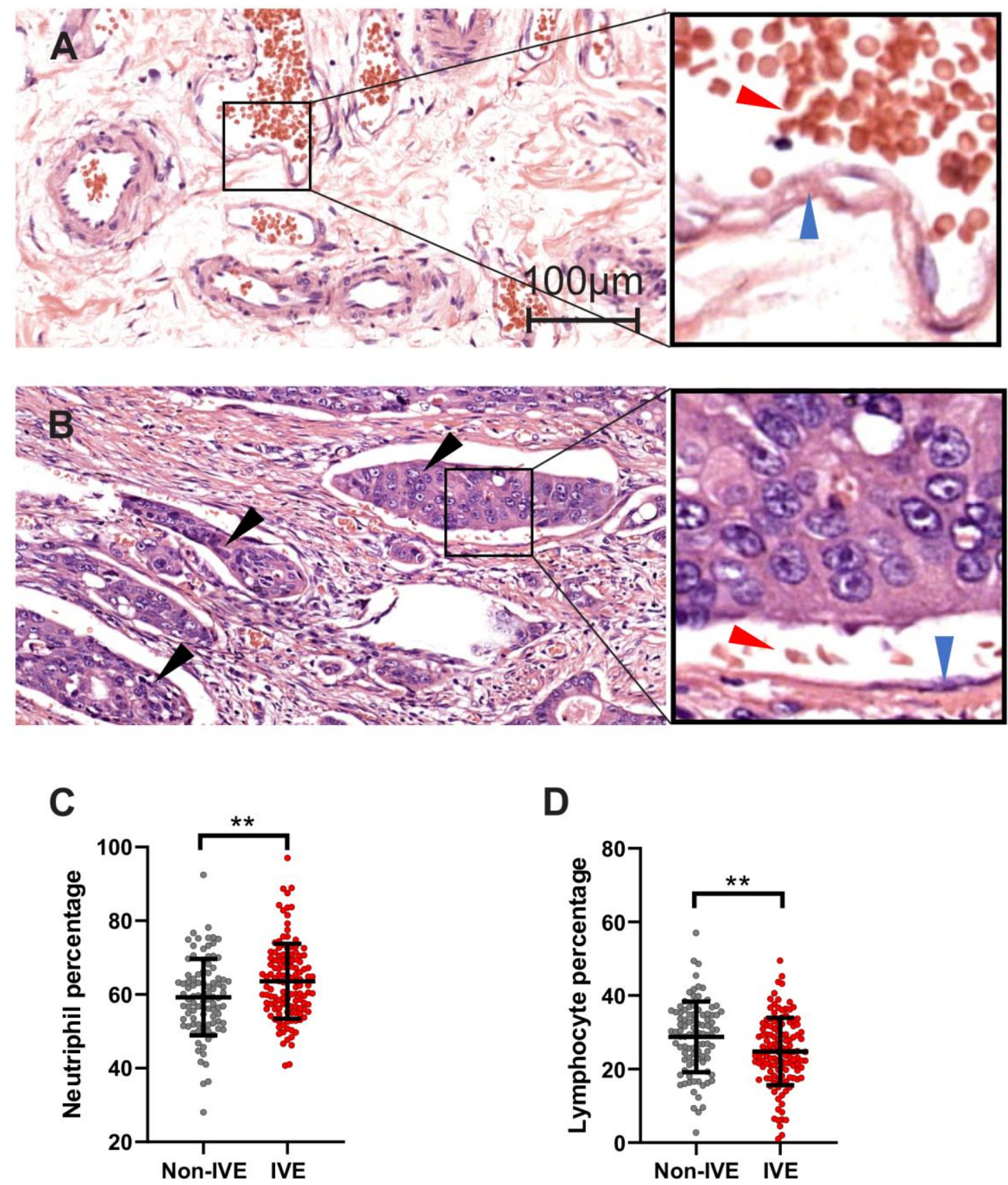

Figure 2. IVE related to peripheral lymphocyte and neutrophil percentage. (A, B) representative H\&E staining images of cancer tissue without IVE (A) and with IVE (B). IVE is indicated by black arrows, the wall of vessels and red cells are indicated by blue arrows and red arrows, respectively. (C, D) IVE patients had higher neutrophil percentage (C) and lower lymphocyte percentage (D) relative to non-IVE patients. $(* *, P<0.01)$. 
those patients can benefit from other treatment such as target therapy.

IVE was observed decades ago [4, 5, 11], but the molecular mechanism is still unclear due to a lack of validated models that mimic the process. Chronic inflammation and immune response are closely related to the development of many cancers including CRC [26, 27]. We previously found some indices related to inflammatory and immune response could serve as

A

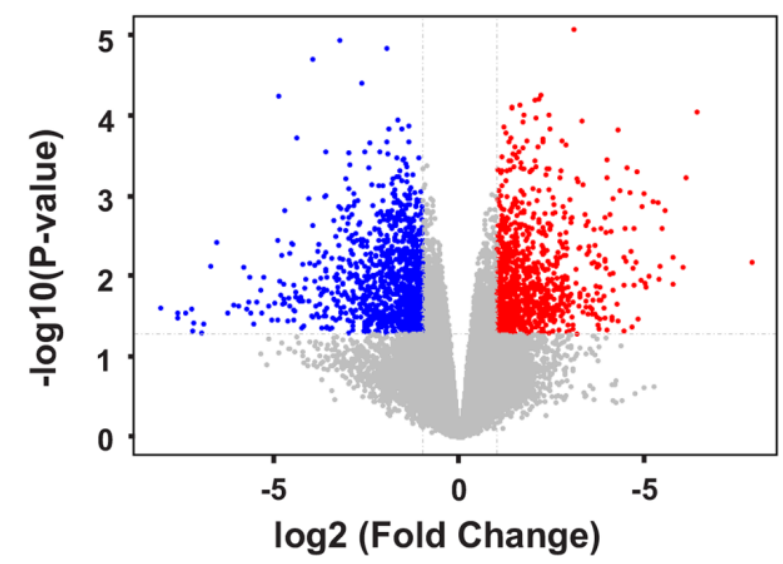

prognostic predictors [28]. In this study, CRC with IVE correlated with higher neutrophil and lower lymphocyte percentage. Patients who showed obstruction symptoms also had higher chances of developing IVE. Moreover, the enrichment of gene sets including chronic inflammation pathway and negative regulation of lymphocyte-mediated immunity in IVE was observed. These findings suggest systematic or local inflammatory and immune responses may contribute to CRC metastasis following IVE formation.
B

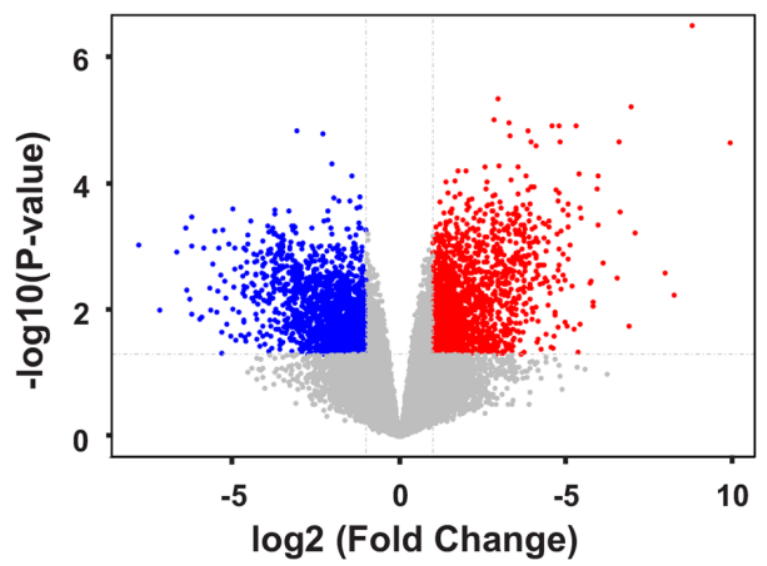

C
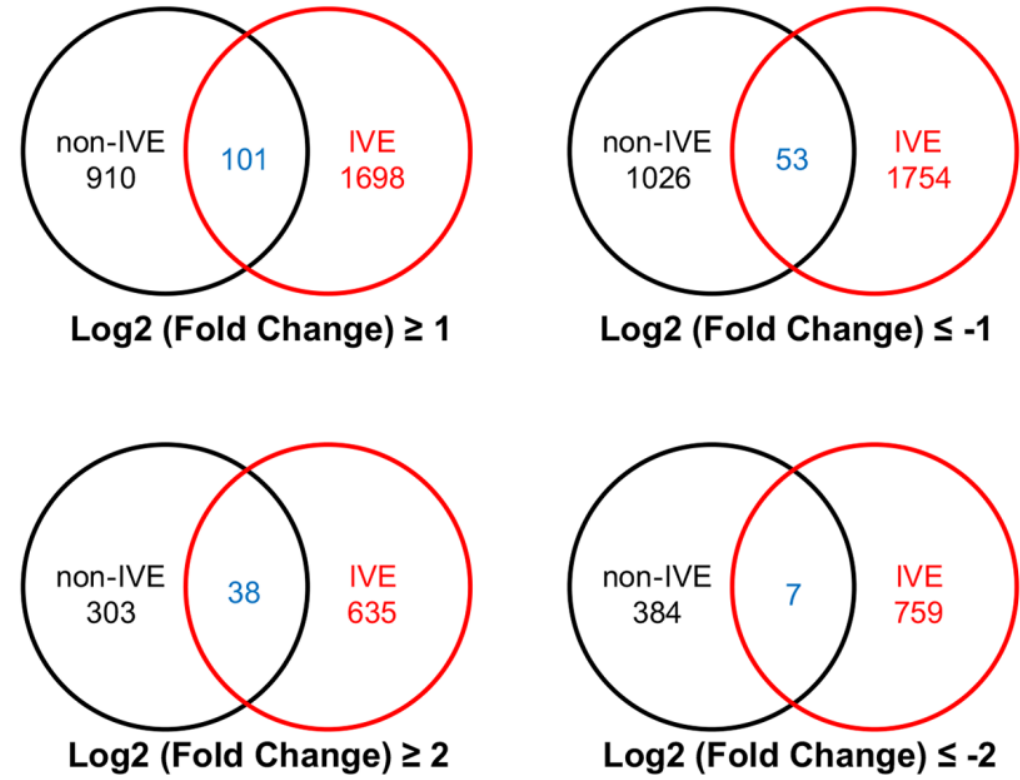

Figure 3. Analysis of DEGs in non-IVE and IVE groups compared with their paired normal groups. (A) Volcano plot of DEGs between the IVE and paired group 1. (B) Volcano plot of DEGs between IVE and paired group 2. For (A, B), Genes significantly up-regulated are highlighted in red while down-regulated genes are highlighted in blue. The $P$-value threshold and cutoff of absolute fold change were $<0.05$ and $>2$, respectively. (C) Venn diagrams indicating the number of DEGs in each group and common DEGs. IVE, IVE group versus paired group 1; non-IVE: non-IVE group versus paired group 2. 
A

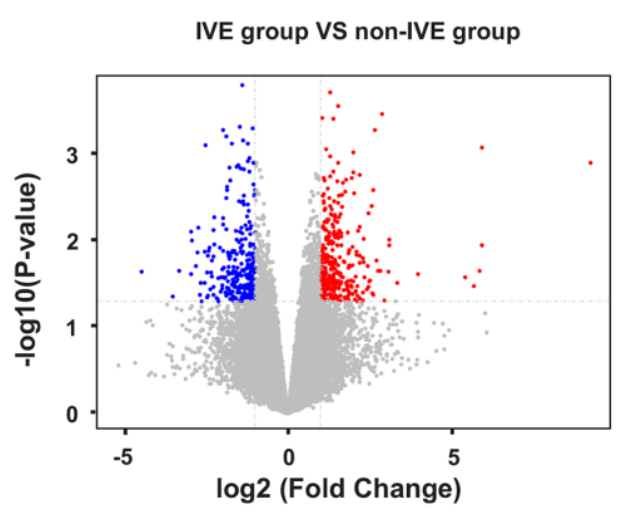

B
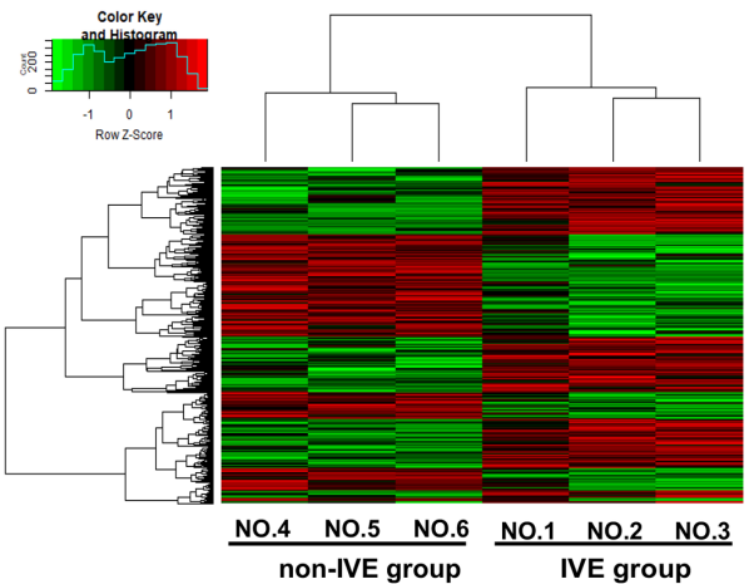

Figure 4. DEGs and hierarchical clustering analysis in the IVE group compared with the non-IVE group. (A) Volcano plot of DEGs between the IVE group and the non-IVE group. Genes significantly up-regulated are highlighted in red while down-regulated genes are highlighted in blue. The $P$-value threshold and cutoff of absolute fold change were $<0.05$ and $>2$, respectively. (B) Heat map clustering of gene expression in cancer tissue resected from six patients. Each column represents 1 individual patient tumor and each row represents 1 gene. Color indicate normalized counts of each gene, with red representing higher expression and green relatively lower expression.

A

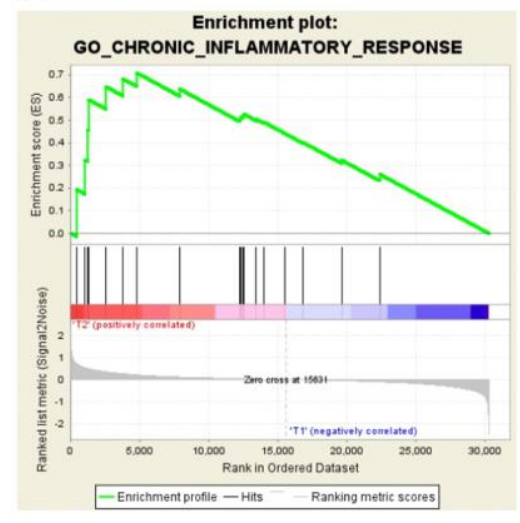

D

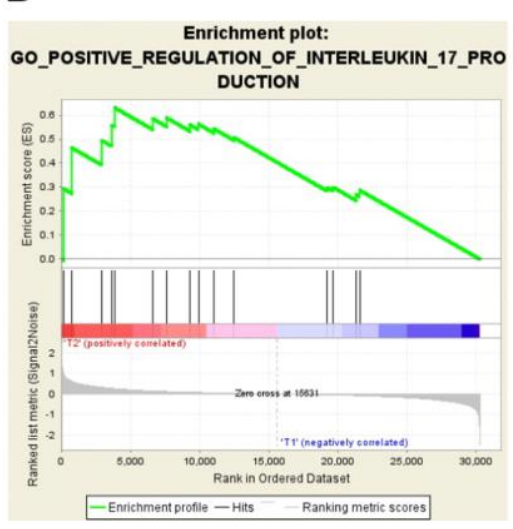

B

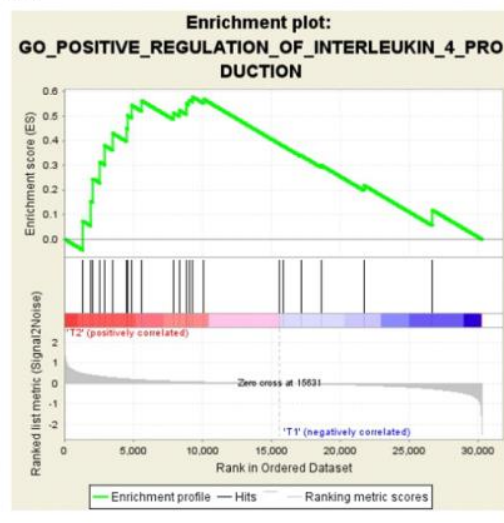

E

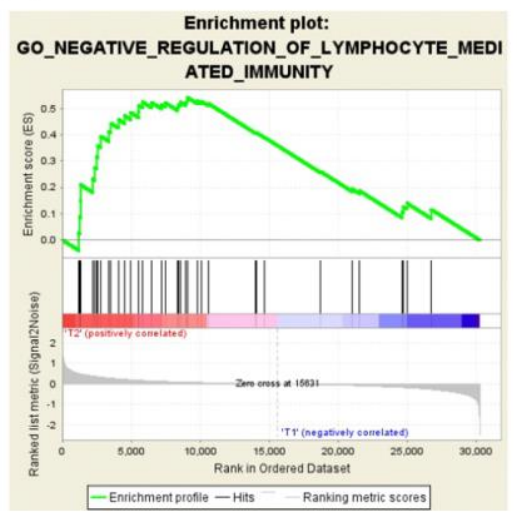

C

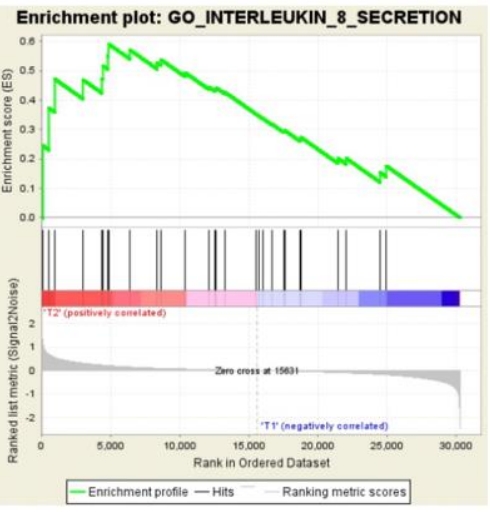

$\mathbf{F}$

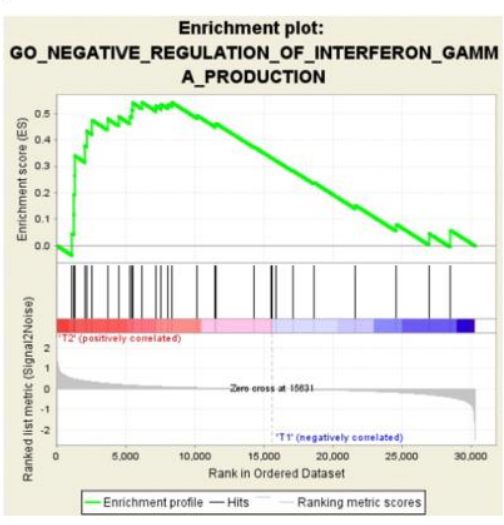

Figure 5. GSEA-enrichment plots of representative gene sets in the IVE group. (A) chronic inflammatory response (NES,1.777; FDR q-value, 0.012; NOM p-value, <0.001). (B) positive regulation of IL-4 production (NES, 1.549; FDR q-value, 0.023; NOM p-value, 0.028). (C) IL-8 secretion (NES, 1.654; FDR q-value, 0.034; NOM p-value, 0.006). (D) positive regulation of IL-17 production (NES, 1.572; FDR q-value, 0.025; NOM p-value, 0.021). (E) negative regulation of lymphocyte mediated immunity (NES, 1.631; FDR q-value, 0.022; NOM p-value, 0.009). (F) negative regulation of IFNy production (NES, 1.561; FDR q-value, 0.024; NOM p-value, 0.031). 
The tumor microenvironment, which consists of immune cells, stromal cells, blood vessels, extracellular matrix, chemokines, and cytokines, interacts with tumor cells consistently and promote evolution and immune tolerance of cancerous cells $[29,30]$. The tumor microenvironment is heterogeneous [31] and can also contribute to tumor heterogeneity along with genetic divergence and epigenetic regulation [32]. To characterize the tumor microenvironment, a microarraybased analysis was performed in our study. The number of DEGs in cancer tissue with IVE is almost double that in cancer tissue without IVE when compared with their paired noncancerous tissue, and only a very small number of DEGs were shared by both groups. DEGs clustering analysis also confirmed the distinguishing features between the two groups. Here one limitation is

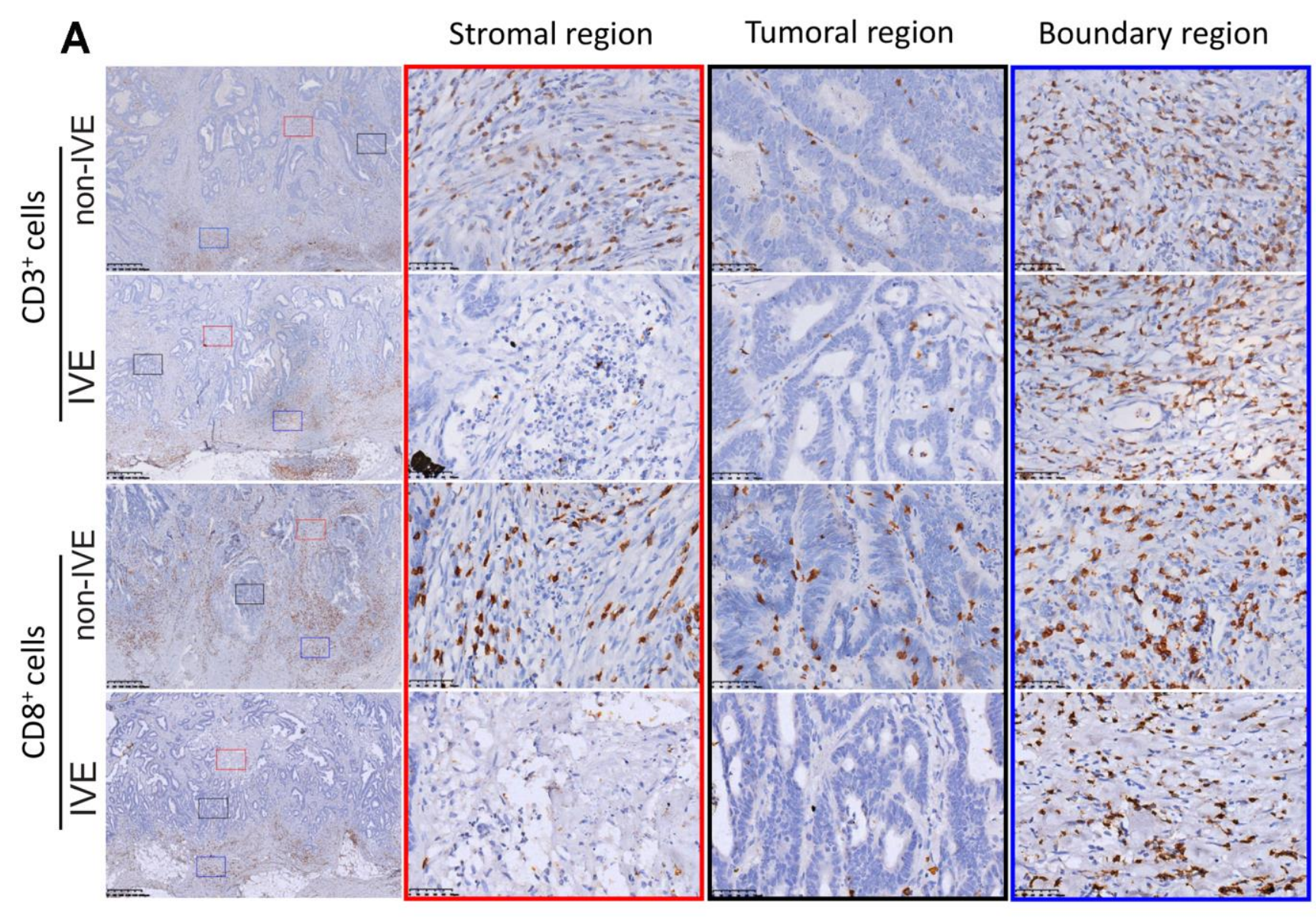

B

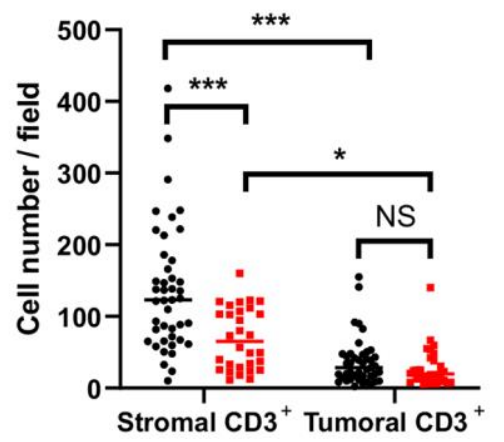

C

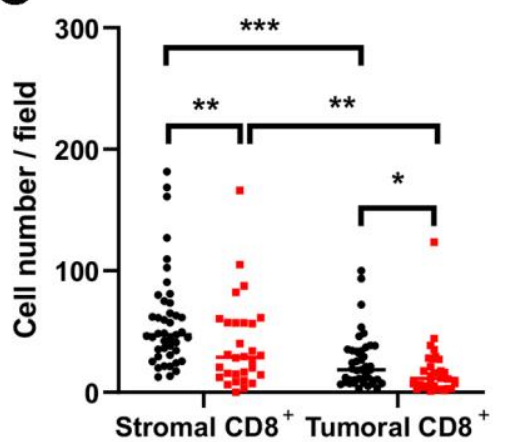

D

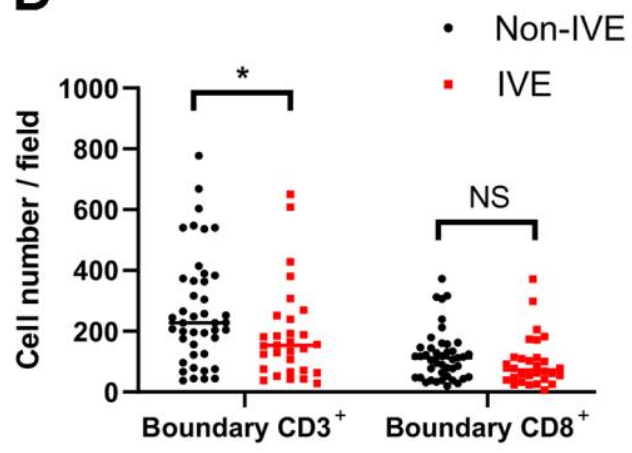

Figure 6. CRC with IVE had fewer $\mathrm{CD} 3^{+}$and $\mathrm{CD} 8^{+}$TILs. (A) representative images of $\mathrm{CD} 3^{+}$and $\mathrm{CD} 8^{+}$TILs in different regions of tumors with or without IVE. Stromal, tumoral, and boundary regions are indicated by red, black and blue rectangles, respectively. (B) tumor with IVE had fewer stromal CD3 ${ }^{+}$TILs compared with non-IVE. (C) tumors with IVE had fewer stromal and tumoral CD8 ${ }^{+}$TILs compared with non-IVE. (D) tumors with IVE had fewer boundary CD3 ${ }^{+}$TILs but similar CD3 ${ }^{+}$TILs. (NS, $\left.P>0.05 ;{ }^{*}, P<0.05 ;{ }^{* *}, P<0.01 ; * * *, P<0.001\right)$. 
the low number of patients which may lead to some bias. Among those top ten up/down regulated genes in IVE group, some genes have been studied in CRC. Those including REG1A, KLK8, KLK12 and MAGEA are up regulated in IVE group, among which REG1A and KLK8 predict poor prognosis in CRC [33, 34], while silence of KLK12 and MAGEA can inhibit CRC growth and promote cell death $[35,36]$. Interestingly, cytoplasmic ASPN have been found to promote cell migration and indicate a poor prognosis in colorectal cancer [37], and elevated DKK1 expression is associated with recurrence and impairs the response to PD-1 blockade in dMMR CRC [38], while both of which are down regulated in IVE group. PTF1A has been well studied in pancreatic cancer. It can block pancreatic tumorigenesis and re-differentiate pancreatic cancer precursors to exocrine cells [37]. DRD2 serves as tumor suppressor and triggers pyroptosis in breast cancer, while its overexpression promotes CRC progression [39, 40]. Furth research should be carried out to reveal more functions of those genes.

The survival, proliferation, and metastasis of cancer cells are influenced by many kinds of cytokines interacting with them in the tumor microenvironment. A previous study showed IVE was characterized by positively expressing CD133, a surface marker of stemlike cells [3]. IL-4 has been found to maintain the stemness of CRC and mediate resistance to apoptosis via the autocrine response. Blocking IL-4 can synergize with chemotherapeutic drugs to overcome the resistance of CSCs to apoptosis [41, 42]. Tumor-derived IL-8 can bias the tumor microenvironment towards an immunosuppressive state and promote tumor invasion, metastasis and resistance to chemotherapy. Angiogenesis of endothelial cells upon IL-8 stimulation is necessary for tumor growth by delivering essential nutrients [43]. Similarly, Th17 cells and IL-17 contribute to carcinogenesis, angiogenesis, and tumor resistance to anti-angiogenic therapy and predict poor prognosis of CRC [44-47]. On the contrary, IFN $\gamma$ has antitumor effects by both acting on tumor cells directly and remodeling the tumor microenvironment, including function modulation of tumor-infiltrating immune cells and stromal cells. Resistance to checkpoint blockade was found to be associated with genomic defects in the IFN $\gamma$ pathway in tumor cells [48]. Our GSEA results indicated that pathways inducing IL-4, IL-8 and IL-17 production were activated in the IVE group while IFN $\gamma$ production was inhibited. This may contribute to IVE development, which may ultimately lead to an immunosuppressive tumor microenvironment. TILs with specific CD3 and CD8 markers existing in different compartments of the tumor were examined to evaluate the Immunoscore in CRC tumors [49]. Generally, higher levels of $\mathrm{CD}^{+}$or $\mathrm{CD} 8^{+}$TILs generally correlate with a better prognosis in CRC patients $[50,51]$. In this study, we found a significant difference in both $\mathrm{CD}^{+}$and $\mathrm{CD}^{+}$TILs related to different regions between IVE and non-IVE tumors, indicating a relatively immunosuppressive tumor microenvironment within an IVE tumor. Additionally, immune heterogeneity was observed within a single tumor for the distribution of TILs was quite different.

\section{CONCLUSIONS}

Stage III CRC patients with IVE have a worse prognosis compared to those without IVE. The tumor microenvironment, which is characterized by chronic inflammation and immunosuppression, may be responsible for IVE development. For both distinct clinical and biological behavior, consideration should be made whether it is appropriate to consider all stage III CRC as regional tumors. As indicated by the findings in this paper, the presence of IVE may suggest tumor metastasis.

\section{AUTHOR CONTRIBUTIONS}

XP, QP and HP conceived and designed the study. XP and QP collected the data. XP and DX wrote the paper. All author contributed to the data analysis and approved the final manuscript.

\section{ACKNOWLEDGMENTS}

Thank you to all the authors' contributions to this study. We thank Liling Li and Qingling Li (Department of Pathology, Xiangya Hospital, Central South University, Changsha, China) for their work on IVE assessment and Darleny Y. Lizardo (Department of Pharmacology and Chemical Biology, UPMC Hillman Cancer Centre, Pittsburgh) for assistance with proofreading of English grammar.

\section{CONFLICTS OF INTEREST}

The authors declare that they have no conflicts of interest.

\section{FUNDING}

This work was supported by the Nature Scientific Foundation of China, grant number: 81702956; the Strategy-Oriented Special Project of Central South University in China, grant number: ZLXD2017003.

\section{REFERENCES}

1. Bray F, Ferlay J, Soerjomataram I, Siegel RL, Torre LA, Jemal A. Global cancer statistics 2018: GLOBOCAN 
estimates of incidence and mortality worldwide for 36 cancers in 185 countries. CA Cancer J Clin. 2018; 68:394-424.

https://doi.org/10.3322/caac.21492

PMID:30207593

2. Krasna MJ, Flancbaum L, Cody RP, Shneibaum S, Ben Ari G. Vascular and neural invasion in colorectal carcinoma. Incidence and prognostic significance. Cancer. 1988; 61:1018-23. https://doi.org/10.1002/1097-0142(19880301)61:5< 1018::aid-cncr2820610527>3.0.co;2-h PMID: $\underline{338045}$

3. Pei $Q$, Zhu H, Tan F, Yu N, Zhou Z, Zhou Y, Song $X$, Li Y, Tao Y, Zhang S, Li L, Li Q, Pei H. Intravascular emboli is an independent risk factor for the prognosis of stage III colorectal cancer patients after radical surgery. Oncotarget. 2016; 7:57268-76.

https://doi.org/10.18632/oncotarget.11266 PMID:27528226

4. Talbot IC, Ritchie S, Leighton MH, Hughes AO, Bussey $\mathrm{HJ}$, Morson BC. The clinical significance of invasion of veins by rectal cancer. Br J Surg. 1980; 67:439-42. https://doi.org/10.1002/bjs.1800670619 PMID: $\underline{7388345}$

5. Talbot IC, Ritchie S, Leighton M, Hughes AO, Bussey HJ, Morson BC. Invasion of veins by carcinoma of rectum: method of detection, histological features and significance. Histopathology. 1981; 5:141-63. https://doi.org/10.1111/j.1365-2559.1981.tb01774.x PMID: 7216178

6. Valastyan S, Weinberg RA. Tumor metastasis: molecular insights and evolving paradigms. Cell. 2011; 147:275-92.

https://doi.org/10.1016/j.cell.2011.09.024 PMID:22000009

7. Siravegna G, Mussolin B, Venesio T, Marsoni S, Seoane J, Dive C, Papadopoulos N, Kopetz S, Corcoran RB, Siu LL, Bardelli A. How liquid biopsies can change clinical practice in oncology. Ann Oncol. 2019; 30:1580-90. https://doi.org/10.1093/annonc/mdz227 PMID:31373349

8. Zhong $X$, Zhang H, Zhu Y, Liang Y, Yuan Z, Li J, Li J, Li X, Jia $Y$, He T, Zhu J, Sun $Y$, Jiang $W$, et al. Circulating tumor cells in cancer patients: developments and clinical applications for immunotherapy. Mol Cancer. 2020; 19:15.

https://doi.org/10.1186/s12943-020-1141-9

PMID:31980023

9. Tamminga M, Groen HJ. Circulating tumor cells are prognostic in SCLC, but still lack clinical application. Ann Oncol. 2019; 30:1031-33. https://doi.org/10.1093/annonc/mdz162
PMID:31095269

10. Zhang L, Liang $Y$, Li S, Zeng F, Meng Y, Chen Z, Liu S, Tao $\mathrm{Y}, \mathrm{Yu} F$. The interplay of circulating tumor DNA and chromatin modification, therapeutic resistance, and metastasis. Mol Cancer. 2019; 18:36.

https://doi.org/10.1186/s12943-019-0989-z

PMID:30849971

11. van Nagell JR Jr, Donaldson ES, Wood EG, Parker JC Jr. The significance of vascular invasion and lymphocytic infiltration in invasive cervical cancer. Cancer. 1978; 41:228-34.

https://doi.org/10.1002/1097-0142(197801)41:1< 228::aid-cncr2820410131>3.0.c0;2-6 PMID:626931

12. Maehara $Y$, Kabashima A, Koga T, Tokunaga E, Takeuchi H, Kakeji Y, Sugimachi K. Vascular invasion and potential for tumor angiogenesis and metastasis in gastric carcinoma. Surgery. 2000; 128:408-16.

https://doi.org/10.1067/msy.2000.107265

PMID:10965312

13. Comoli P, Chabannon C, Koehl U, Lanza F, UrbanoIspizua A, Hudecek $M$, Ruggeri A, Secondino S, Bonini C, Pedrazzoli $P$, and European Society for Blood and Marrow Transplantation, Cellular Therapy and Immunobiology Working Party - Solid Tumor Sub-committee. Development of adaptive immune effector therapies in solid tumors. Ann Oncol. 2019; 30:1740-50.

https://doi.org/10.1093/annonc/mdz285 PMID:31435646

14. Dienstmann R, Villacampa G, Sveen A, Mason MJ, Niedzwiecki D, Nesbakken A, Moreno V, Warren RS, Lothe RA, Guinney J. Relative contribution of clinicopathological variables, genomic markers, transcriptomic subtyping and microenvironment features for outcome prediction in stage II/III colorectal cancer. Ann Oncol. 2019; 30:1622-29.

https://doi.org/10.1093/annonc/mdz287 PMID:31504112

15. Siegel RL, Miller KD, Fedewa SA, Ahnen DJ, Meester RG, Barzi A, Jemal A. Colorectal cancer statistics, 2017. CA Cancer J Clin. 2017; 67:177-93. https://doi.org/10.3322/caac.21395 PMID:28248415

16. Song X, Xie D, Xia X, Tan F, Pei Q, Li Y, Zhou Z, Zhou Y, Li C, Wang K, Pei H. Role of SSH1 in colorectal cancer prognosis and tumor progression. I Gastroenterol Hepatol. 2020; 35:1180-88.

https://doi.org/10.1111/igh.15001 PMID:32020663

17. Subramanian A, Tamayo $P$, Mootha VK, Mukherjee $S$, Ebert BL, Gillette MA, Paulovich A, Pomeroy SL, Golub TR, Lander ES, Mesirov JP. Gene set enrichment analysis: a knowledge-based approach for interpreting 
genome-wide expression profiles. Proc Natl Acad Sci USA. 2005; 102:15545-50.

https://doi.org/10.1073/pnas.0506580102

PMID:16199517

18. Zhang CM, Lv JF, Gong L, Yu LY, Chen XP, Zhou HH, Fan L. Role of Deficient Mismatch Repair in the Personalized Management of Colorectal Cancer. Int J Environ Res Public Health. 2016; 13:892.

https://doi.org/10.3390/ijerph13090892 PMID:27618077

19. Benson $A B$, Venook AP, Al-Hawary MM, Cederquist $L$, Chen YJ, Ciombor KK, Cohen S, Cooper HS, Deming D, Engstrom PF, Garrido-Laguna I, Grem JL, Grothey A, et al. NCCN Guidelines Insights: Colon Cancer, Version 2.2018. J Natl Compr Canc Netw. 2018; 16:359-69. https://doi.org/10.6004/jnccn.2018.0021 PMID:29632055

20. Edge SB, Compton CC. The American Joint Committee on Cancer: the 7th edition of the AJCC cancer staging manual and the future of TNM. Ann Surg Oncol. 2010; 17:1471-74.

https://doi.org/10.1245/s10434-010-0985-4 PMID:20180029

21. Westenend PJ, Meurs CJ, Damhuis RA. Tumour size and vascular invasion predict distant metastasis in stage I breast cancer. Grade distinguishes early and late metastasis. J Clin Pathol. 2005; 58:196-201. https://doi.org/10.1136/icp.2004.018515 PMID:15677542

22. Li P, Ling YH, Zhu CM, Hu WM, Zhang XK, Luo RZ, He JH, Yun JP, Li YF, Cai MY. Vascular invasion as an independent predictor of poor prognosis in nonmetastatic gastric cancer after curative resection. Int J Clin Exp Pathol. 2015; 8:3910-18.

PMID:26097575

23. Ciardiello F, Normanno N, Martinelli E, Troiani T, Pisconti S, Cardone C, Nappi A, Bordonaro AR, Rachiglio M, Lambiase M, Latiano TP, Modoni G, Cordio $\mathrm{S}$, et al, and CAPRI-GOIM investigators. Cetuximab continuation after first progression in metastatic colorectal cancer (CAPRI-GOIM): a randomized phase II trial of FOLFOX plus cetuximab versus FOLFOX. Ann Oncol. 2016; 27:1055-61.

https://doi.org/10.1093/annonc/mdw136

PMID:27002107

24. Kopetz S, Grothey A, Yaeger R, Van Cutsem E, Desai J, Yoshino T, Wasan H, Ciardiello F, Loupakis F, Hong YS, Steeghs N, Guren TK, Arkenau HT, et al. Encorafenib, Binimetinib, and Cetuximab in BRAF V600E-Mutated Colorectal Cancer. N Engl J Med. 2019; 381:1632-43. https://doi.org/10.1056/NEJMoa1908075 PMID:31566309
25. Qin S, Li J, Wang L, Xu J, Cheng Y, Bai Y, Li W, Xu N, Lin LZ, Wu Q, Li Y, Yang J, Pan H, et al. Efficacy and Tolerability of First-Line Cetuximab Plus Leucovorin, Fluorouracil, and Oxaliplatin (FOLFOX-4) Versus FOLFOX-4 in Patients With RAS Wild-Type Metastatic Colorectal Cancer: The Open-Label, Randomized, Phase III TAILOR Trial. J Clin Oncol. 2018; 36:3031-39. https://doi.org/10.1200/JCO.2018.78.3183 PMID:30199311

26. Elinav E, Nowarski R, Thaiss CA, Hu B, Jin C, Flavell RA. Inflammation-induced cancer: crosstalk between tumours, immune cells and microorganisms. Nat Rev Cancer. 2013; 13:759-71. https://doi.org/10.1038/nrc3611 PMID:24154716

27. Chen DS, Mellman I. Oncology meets immunology: the cancer-immunity cycle. Immunity. 2013; 39:1-10. https://doi.org/10.1016/i.immuni.2013.07.012 PMID:23890059

28. Song X, Zhu H, Pei Q, Tan F, Li C, Zhou Z, Zhou Y, Yu N, $\mathrm{Li} Y$, Pei H. Significance of inflammation-based indices in the prognosis of patients with non-metastatic colorectal cancer. Oncotarget. 2017; 8:45178-89. https://doi.org/10.18632/oncotarget.16774 PMID:28423351

29. Wang $M$, Zhao J, Zhang L, Wei F, Lian $Y$, Wu Y, Gong Z, Zhang S, Zhou J, Cao K, Li X, Xiong W, Li G, et al. Role of tumor microenvironment in tumorigenesis. J Cancer. 2017; 8:761-73. https://doi.org/10.7150/jca.17648 PMID:28382138

30. Spill F, Reynolds DS, Kamm RD, Zaman MH. Impact of the physical microenvironment on tumor progression and metastasis. Curr Opin Biotechnol. 2016; 40:41-48. https://doi.org/10.1016/i.copbio.2016.02.007 PMID:26938687

31. Thorsson V, Gibbs DL, Brown SD, Wolf D, Bortone DS, Ou Yang TH, Porta-Pardo E, Gao GF, Plaisier CL, Eddy JA, Ziv E, Culhane AC, Paull EO, et al, and Cancer Genome Atlas Research Network. The Immune Landscape of Cancer. Immunity. 2018; 48:812-30.e14. https://doi.org/10.1016/j.immuni.2018.03.023 PMID:29628290

32. Yang L, Lin PC. Mechanisms that drive inflammatory tumor microenvironment, tumor heterogeneity, and metastatic progression. Semin Cancer Biol. 2017; 47:185-95.

https://doi.org/10.1016/i.semcancer.2017.08.001 PMID:28782608

33. Astrosini C, Roeefzaad C, Dai YY, Dieckgraefe BK, Jöns $T$, Kemmner W. REG1A expression is a prognostic marker in colorectal cancer and associated with peritoneal carcinomatosis. Int J Cancer. 2008; 123:409-13. 
https://doi.org/10.1002/ijc.23466 PMID:18452172

34. Liu X, Quan B, Tian Z, Xi H, Jia G, Wang H, Zhang L, Liu R, Ma C, Han F, Li H, Yuan F. Elevated expression of KLK8 predicts poor prognosis in colorectal cancer. Biomed Pharmacother. 2017; 88:595-602.

https://doi.org/10.1016/j.biopha.2017.01.112

PMID:28142115

35. Xia Y, Tang G, Guo M, Xu T, Chen H, Lin Z, Li Y, Chen Y, Zhu B, Liu H, Cao J. Silencing KLK12 expression via RGDfC-decorated selenium nanoparticles for the treatment of colorectal cancer in vitro and in vivo. Mater Sci Eng C Mater Biol Appl. 2020; 110:110594. https://doi.org/10.1016/j.msec.2019.110594 PMID:32204058

36. Wu F, Liu F, Dong L, Yang H, He X, Li L, Zhao L, Jin S, Li G. miR-1273g silences MAGEA3/6 to inhibit human colorectal cancer cell growth via activation of AMPK signaling. Cancer Lett. 2018; 435:1-9.

https://doi.org/10.1016/i.canlet.2018.07.031

PMID:30056111

37. Li H, Zhang Z, Chen L, Sun X, Zhao Y, Guo Q, Zhu S, Li P, Min L, Zhang S. Cytoplasmic Asporin promotes cell migration by regulating TGF- $\beta / \mathrm{Smad} 2 / 3$ pathway and indicates a poor prognosis in colorectal cancer. Cell Death Dis. 2019; 10:109.

https://doi.org/10.1038/s41419-019-1376-9

PMID:30728352

38. Sui $Q$, Liu $D$, Jiang $W$, Tang J, Kong $L$, Han $K$, Liao L, Li Y, Ou Q, Xiao B, Liu G, Ling Y, Chen J, et al. Dickkopf 1 impairs the tumor response to PD-1 blockade by inactivating $\mathrm{CD} 8+\mathrm{T}$ cells in deficient mismatch repair colorectal cancer. J Immunother Cancer. 2021; 9:e001498.

https://doi.org/10.1136/jitc-2020-001498

PMID:33782107

39. Lee H, Shim S, Kong JS, Kim MJ, Park S, Lee SS, Kim A. Overexpression of dopamine receptor D2 promotes colorectal cancer progression by activating the $\beta$ catenin/ZEB1 axis. Cancer Sci. 2021. [Epub ahead of print].

https://doi.org/10.1111/cas.15026 PMID:34118099

40. Tan Y, Sun R, Liu L, Yang D, Xiang Q, Li L, Tang J, Qiu Z, Peng W, Wang $Y$, Ye L, Ren G, Xiang T. Tumor suppressor DRD2 facilitates M1 macrophages and restricts NF-KB signaling to trigger pyroptosis in breast cancer. Theranostics. 2021; 11:5214-31.

https://doi.org/10.7150/thno.58322 PMID:33859743

41. Francipane MG, Alea MP, Lombardo $\mathrm{Y}$, Todaro $\mathrm{M}$, Medema JP, Stassi G. Crucial role of interleukin-4 in the survival of colon cancer stem cells. Cancer Res. 2008; 68:4022-25.

https://doi.org/10.1158/0008-5472.CAN-07-6874
PMID:18519657

42. Hallett MA, Venmar KT, Fingleton B. Cytokine stimulation of epithelial cancer cells: the similar and divergent functions of IL-4 and IL-13. Cancer Res. 2012; 72:6338-43.

https://doi.org/10.1158/0008-5472.CAN-12-3544 PMID:23222300

43. Alfaro C, Sanmamed MF, Rodríguez-Ruiz ME, Teijeira Á, Oñate C, González Á, Ponz M, Schalper KA, PérezGracia JL, Melero I. Interleukin-8 in cancer pathogenesis, treatment and follow-up. Cancer Treat Rev. 2017; 60:24-31.

https://doi.org/10.1016/i.ctrv.2017.08.004 PMID:28866366

44. Li TJ, Jiang YM, Hu YF, Huang L, Yu J, Zhao LY, Deng HJ, Mou TY, Liu H, Yang Y, Zhang Q, Li GX. Interleukin-17Producing Neutrophils Link Inflammatory Stimuli to Disease Progression by Promoting Angiogenesis in Gastric Cancer. Clin Cancer Res. 2017; 23:1575-85. https://doi.org/10.1158/1078-0432.CCR-16-0617 PMID:27620275

45. Chung AS, Wu X, Zhuang G, Ngu H, Kasman I, Zhang J, Vernes JM, Jiang Z, Meng YG, Peale FV, Ouyang W, Ferrara N. An interleukin-17-mediated paracrine network promotes tumor resistance to anti-angiogenic therapy. Nat Med. 2013; 19:1114-23. https://doi.org/10.1038/nm.3291 PMID:23913124

46. Hurtado CG, Wan F, Housseau F, Sears CL. Roles for Interleukin 17 and Adaptive Immunity in Pathogenesis of Colorectal Cancer. Gastroenterology. 2018; 155:1706-15.

https://doi.org/10.1053/j.gastro.2018.08.056 PMID: $\underline{30218667}$

47. Chen J, Chen Z. The effect of immune microenvironment on the progression and prognosis of colorectal cancer. Med Oncol. 2014; 31:82. https://doi.org/10.1007/s12032-014-0082-9 PMID:25034363

48. Ivashkiv LB. IFNץ: signalling, epigenetics and roles in immunity, metabolism, disease and cancer immunotherapy. Nat Rev Immunol. 2018; 18:545-58. https://doi.org/10.1038/s41577-018-0029-z PMID:29921905

49. Donnem T, Kilvaer TK, Andersen S, Richardsen E, Paulsen EE, Hald SM, Al-Saad S, Brustugun OT, Helland A, Lund-Iversen M, Solberg S, Gronberg BH, Wahl SG, et al. Strategies for clinical implementation of TNMImmunoscore in resected nonsmall-cell lung cancer. Ann Oncol. 2016; 27:225-32. https://doi.org/10.1093/annonc/mdv560 PMID:26578726

50. Idos GE, Kwok J, Bonthala N, Kysh L, Gruber SB, Qu C. 
The Prognostic Implications of Tumor Infiltrating Lymphocytes in Colorectal Cancer: A Systematic Review and Meta-Analysis. Sci Rep. 2020; 10:3360.

https://doi.org/10.1038/s41598-020-60255-4

PMID:32099066

51. Mei Z, Liu Y, Liu C, Cui A, Liang Z, Wang G, Peng H, Cui $L$, Li C. Tumour-infiltrating inflammation and prognosis in colorectal cancer: systematic review and metaanalysis. Br J Cancer. 2014; 110:1595-605.

https://doi.org/10.1038/bjc.2014.46 PMID:24504370 


\section{SUPPLEMENTARY MATERIALS}

\section{Supplementary Figure}

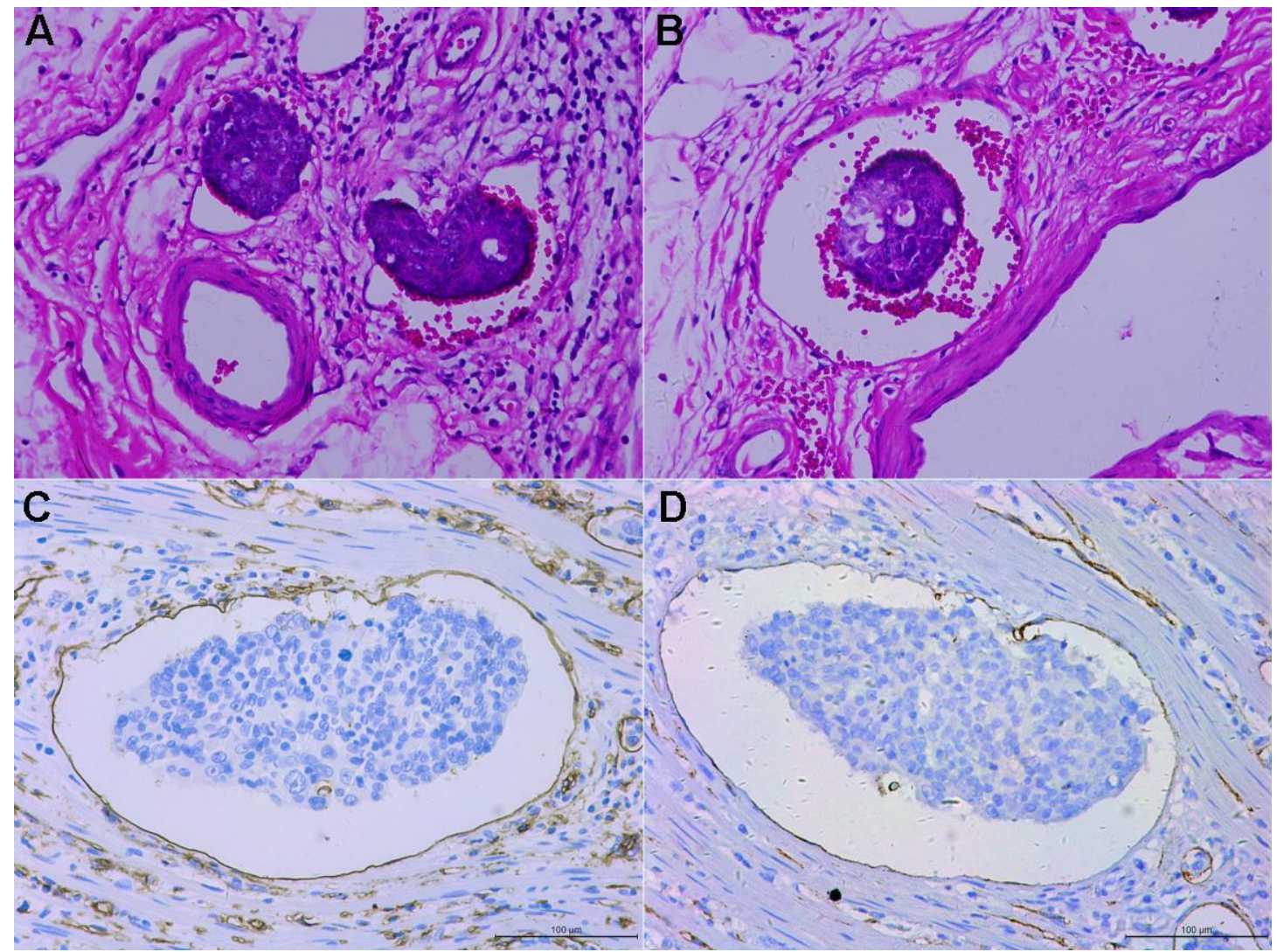

Supplementary Figure 1. Intravascular emboli (IVE) diagnostic criteria by HE and IHC staining. (A, B) IVE diagnosed by HE staining: a cluster of tumor cells in an endothelium-lined space either surrounded by a rim of smooth muscle or containing red blood cells; (C, D) IVE diagnosed by IHC staining: blood vessel endothelium strongly stained by CD34 antibody but not stained by D2-40. 


\section{Supplementary Tables}

Supplementary Table 1. Baseline demographic and clinical characteristics of patients.

\begin{tabular}{|c|c|c|c|c|c|}
\hline Parameters & $\mathbf{N}$ & Range & Minimum & Maximum & Mean \\
\hline Age (year) & 220 & 69.00 & 14.00 & 83.00 & 55.710 \\
\hline Total protein $(\mathrm{g} / \mathrm{dL})$ & 220 & 35.50 & 48.10 & 83.60 & 66.689 \\
\hline Albumin $(\mathrm{g} / \mathrm{dL})$ & 220 & 48.30 & 4.10 & 52.40 & 39.883 \\
\hline Globulin (g/dL) & 219 & 26.40 & 15.30 & 41.70 & 26.646 \\
\hline $\mathrm{A} / \mathrm{G}$ ration & 220 & 1.40 & 0.90 & 2.30 & 1.539 \\
\hline Total bilirubin $(\mu \mathrm{mol} / \mathrm{L})$ & 220 & 59.60 & 0.20 & 59.80 & 10.855 \\
\hline Direct bilirubin $(\mu \mathrm{mol} / \mathrm{L})$ & 220 & 28.10 & 0.90 & 29.00 & 4.163 \\
\hline $\mathrm{ALT}(\mathrm{U} / \mathrm{L})$ & 220 & 149.10 & 3.20 & 152.30 & 19.925 \\
\hline AST (U/L) & 220 & 104.30 & 9.90 & 114.20 & 22.488 \\
\hline Urea $(\mathrm{mmol} / \mathrm{L})$ & 220 & 13.50 & 1.16 & 14.66 & 4.677 \\
\hline Creatinine $(\mu \mathrm{mol} / \mathrm{L})$ & 220 & 131.80 & 23.60 & 155.40 & 79.018 \\
\hline Glucose (mmol/L) & 209 & 11.76 & 2.34 & 14.10 & 5.263 \\
\hline Triglyceride $(\mathrm{mmol} / \mathrm{L})$ & 184 & 9.36 & 0.37 & 9.73 & 1.306 \\
\hline Cholesterol (mmol/L) & 184 & 7.28 & 1.47 & 8.75 & 4.540 \\
\hline $\mathrm{HDL}(\mathrm{mmol} / \mathrm{L})$ & 184 & 2.12 & 0.22 & 2.34 & 1.266 \\
\hline $\mathrm{LDL}(\mathrm{mmol} / \mathrm{L})$ & 184 & 22.60 & 0.00 & 22.60 & 2.884 \\
\hline $\mathrm{HDL} / \mathrm{CHO}$ & 184 & 2.11 & 0.15 & 2.26 & 0.295 \\
\hline Potassium (mmol/L) & 220 & 2.60 & 2.42 & 5.02 & 3.985 \\
\hline Sodium (mmol/L) & 220 & 27.60 & 121.10 & 148.70 & 141.606 \\
\hline Chloride (mmol/L) & 220 & 14.70 & 95.40 & 110.10 & 103.829 \\
\hline Calcium (mmol/L) & 220 & 0.88 & 1.69 & 2.57 & 2.254 \\
\hline WBC count $\left(10^{3} / \mathrm{mL}\right)$ & 220 & 13.20 & 2.40 & 15.60 & 6.228 \\
\hline $\mathrm{RBC}$ count $\left(10^{6} / \mathrm{mL}\right)$ & 220 & 3.10 & 2.61 & 5.71 & 4.083 \\
\hline Hemoglobin $(\mathrm{g} / \mathrm{L})$ & 220 & 149.00 & 16.00 & 165.00 & 117.370 \\
\hline Platelet count $\left(10^{3} / \mathrm{mL}\right)$ & 220 & 681.00 & 21.00 & 702.00 & 230.250 \\
\hline Neutrophil count $\left(10^{3} / \mathrm{mL}\right)$ & 220 & 12.60 & 0.90 & 13.50 & 3.961 \\
\hline Lymphocyte count $\left(10^{3} / \mathrm{mL}\right)$ & 220 & 3.80 & 0.10 & 3.90 & 1.573 \\
\hline Monocyte count $\left(10^{3} / \mathrm{mL}\right)$ & 220 & 1.30 & 0.10 & 1.40 & 0.486 \\
\hline Neutrophil percentage (\%) & 220 & 69.00 & 28.00 & 97.00 & 61.733 \\
\hline Lymphocyte percentage (\%) & 220 & 56.00 & 1.00 & 57.00 & 26.495 \\
\hline Monocyte percentage (\%) & 220 & 17.20 & 0.70 & 17.90 & 8.070 \\
\hline Thrombocytocrit (\%) & 220 & 0.50 & 0.00 & 0.50 & 0.202 \\
\hline MPV (fl) & 220 & 9.70 & 6.20 & 15.90 & 8.822 \\
\hline PDW (\%) & 220 & 15.50 & 7.00 & 22.50 & 16.799 \\
\hline PT (second) & 220 & 13.90 & 10.20 & 24.10 & 12.729 \\
\hline INR & 220 & 1.15 & 0.79 & 1.94 & 0.982 \\
\hline APTT (second) & 220 & 28.20 & 23.20 & 51.40 & 34.376 \\
\hline TT (second) & 220 & 63.60 & 13.90 & 77.50 & 17.726 \\
\hline Fibrinogen $(\mathrm{g} / \mathrm{L})$ & 219 & 6.27 & 1.61 & 7.88 & 3.663 \\
\hline
\end{tabular}

Abbreviations: A/G, albumin to globulin ration; ALT, Alanine aminotransferase; AST, Aspartate aminotransferase; HDL, high-density lipoprotein; LDL, low-density lipoprotein; $\mathrm{HDL} / \mathrm{CHO}$, high-density lipoprotein to cholesterol ration; WBC, white blood cell; RBC, red blood cell; MPV, mean platelet volume; PDW, platelet distribution width; PT, prothrombin time; INR, international normalized ratio; APTT, activated partial thromboplastin time; TT, thrombin time. 
Supplementary Table 2. Relationships between clinical characteristics and IVE.

\begin{tabular}{|c|c|c|c|}
\hline Parameters & non-IVE group & IVE group & $P$-value \\
\hline \multicolumn{4}{|l|}{ Age } \\
\hline$\leq 60$ & 55 & 77 & 0.697 \\
\hline$>60$ & 39 & 49 & \\
\hline \multicolumn{4}{|l|}{ Gender } \\
\hline Male & 47 & 79 & 0.060 \\
\hline Female & 47 & 47 & \\
\hline \multicolumn{4}{|l|}{ Location } \\
\hline Left colon & 18 & 23 & 0.241 \\
\hline Right colon & 23 & 20 & \\
\hline Rectum & 53 & 83 & \\
\hline \multicolumn{4}{|l|}{ Invasion depth } \\
\hline $\mathrm{T} 1-2$ & 14 & 9 & 0.063 \\
\hline T3-4 & 80 & 117 & \\
\hline \multicolumn{4}{|c|}{ Lymph node metastasis } \\
\hline $\mathrm{pN} 1$ & 65 & 55 & $<0.001$ \\
\hline $\mathrm{pN} 2$ & 29 & 71 & \\
\hline \multicolumn{4}{|l|}{ Histologic type } \\
\hline Mucinous/mix & 14 & 15 & $<0.001$ \\
\hline Poor & 6 & 43 & \\
\hline Well /Moderate & 74 & 68 & \\
\hline \multicolumn{4}{|l|}{ Tumor Morphology } \\
\hline Ulcerative & 44 & 57 & 0.472 \\
\hline Infiltrating & 3 & 8 & \\
\hline Protruded & 46 & 53 & \\
\hline \multicolumn{4}{|l|}{ Diameter } \\
\hline$<5 \mathrm{~cm}$ & 45 & 73 & 0.070 \\
\hline$\geq 5 \mathrm{~cm}$ & 48 & 47 & \\
\hline \multicolumn{4}{|c|}{ Obstruction symptoms } \\
\hline No & 93 & 113 & 0.008 \\
\hline Yes & 1 & 12 & \\
\hline \multicolumn{4}{|l|}{ CEA (ng/ml) } \\
\hline$<5$ & 64 & 83 & 0.095 \\
\hline$\geq 5$ & 28 & 37 & \\
\hline \multicolumn{4}{|l|}{ CA199 (kU/L) } \\
\hline$<35$ & 77 & 96 & 0.491 \\
\hline$\geq 35$ & 15 & 24 & \\
\hline \multicolumn{4}{|l|}{ CA242 (kU/L) } \\
\hline$<20$ & 73 & 95 & 0.806 \\
\hline$\geq 20$ & 16 & 19 & \\
\hline \multicolumn{4}{|c|}{ Adjuvant chemotherapy } \\
\hline FOLFOX $4 / 6$ & 58 & 78 & 0.737 \\
\hline XELOX & 7 & 10 & \\
\hline Other & 2 & 6 & \\
\hline No chemotherapy & 27 & 32 & \\
\hline
\end{tabular}


Supplementary Table 3. Difference of blood routine and chemistry between groups.

\begin{tabular}{lccc}
\hline Parameters & non-IVE group & IVE group & P-value \\
\hline Total protein $(\mathrm{g} / \mathrm{dL})$ & $66.38 \pm 6.12$ & $66.92 \pm 6.51$ & 0.539 \\
Albumin $(\mathrm{g} / \mathrm{dL})$ & $39.92 \pm 4.39$ & $39.86 \pm 5.34$ & 0.929 \\
Globulin $(\mathrm{g} / \mathrm{dL})$ & $26.47 \pm 4.26$ & $26.78 \pm 4.45$ & 0.600 \\
A/G ration & $1.54 \pm 0.27$ & $1.53 \pm 0.29$ & 0.783 \\
Total bilirubin $(\mu \mathrm{mol} / \mathrm{L})$ & $10.98 \pm 7.40$ & $10.76 \pm 6.01$ & 0.812 \\
Direct bilirubin $(\mu \mathrm{mol} / \mathrm{L})$ & $4.11 \pm 3.31$ & $4.20 \pm 2.47$ & 0.822 \\
ALT $(\mathrm{U} / \mathrm{L})$ & $21.2 \pm 15.82$ & $19.1 \pm 17.07$ & 0.396 \\
AST $(\mathrm{U} / \mathrm{L})$ & $22.51 \pm 9.51$ & $22.47 \pm 13.66$ & 0.980 \\
Urea $(\mathrm{mmol} / \mathrm{L})$ & $4.58 \pm 1.62$ & $4.75 \pm 1.81$ & 0.474 \\
Creatinine $(\mu \mathrm{mol} / \mathrm{L})$ & $74.7 \pm 19.2$ & $82.24 \pm 20.34$ & $\mathbf{0 . 0 0 6}$ \\
Glucose $(\mathrm{mmol} / \mathrm{L})$ & $5.17 \pm 1.08$ & $5.34 \pm 1.34$ & 0.330 \\
Triglyceride $(\mathrm{mmol} / \mathrm{L})$ & $1.29 \pm 1.08$ & $1.32 \pm 1.17$ & 0.828 \\
Cholesterol $(\mathrm{mmol} / \mathrm{L})$ & $4.53 \pm 1.02$ & $4.54 \pm 0.99$ & 0.940 \\
HDL $(\mathrm{mmol} / \mathrm{L})$ & $1.24 \pm 0.26$ & $1.29 \pm 0.32$ & 0.249 \\
LDL $(\mathrm{mmol} / \mathrm{L})$ & $2.77 \pm 0.96$ & $2.97 \pm 2.12$ & 0.424 \\
HDL/CHO & $0.28 \pm 0.07$ & $0.31 \pm 0.20$ & 0.309 \\
Potassium $(\mathrm{mmol} / \mathrm{L})$ & $3.94 \pm 0.43$ & $4.02 \pm 0.38$ & 0.156 \\
Sodium $(\mathrm{mmol} / \mathrm{L})$ & $141.58 \pm 3.48$ & $141.63 \pm 2.73$ & 0.909 \\
Chloride $(\mathrm{mmol} / \mathrm{L})$ & $104.29 \pm 2.82$ & $103.49 \pm 3.10$ & 0.050 \\
Calcium $(\mathrm{mmol} / \mathrm{L})$ & $2.25 \pm 0.13$ & $2.25 \pm 0.12$ & 0.968 \\
WBC count $\left(10^{3} / \mathrm{mL}\right)$ & $6.01 \pm 2.05$ & $6.39 \pm 2.29$ & 0.213 \\
RBC count $(10 / \mathrm{mL})$ & $4.04 \pm 0.58$ & $4.11 \pm 0.58$ & 0.344 \\
Hemoglobin $(\mathrm{g} / \mathrm{L})$ & $116.12 \pm 23.26$ & $118.31 \pm 24.56$ & 0.504 \\
Platelet count $\left(10^{3} / \mathrm{mL}\right)$ & $225.67 \pm 94.72$ & $233.67 \pm 95.28$ & 0.537 \\
Neutrophil count $\left(10^{3} / \mathrm{mL}\right)$ & $3.68 \pm 1.82$ & $4.17 \pm 2.04$ & 0.066 \\
Lymphocyte count $\left(10^{3} / \mathrm{mL}\right)$ & $1.66 \pm 0.59$ & $1.51 \pm 0.65$ & 0.093 \\
Monocyte count $\left(10^{3} / \mathrm{mL}\right)$ & $0.48 \pm 0.18$ & $0.49 \pm 0.20$ & 0.665 \\
Neutrophil percentage $(\%)$ & $59.26 \pm 10.38$ & $63.38 \pm 10.17$ & $\mathbf{0 . 0 0 2}$ \\
Lymphocyte percentage $(\%)$ & $28.77 \pm 9.62$ & $24.80 \pm 9.19$ & $\mathbf{0 . 0 0 2}$ \\
Monocyte percentage $(\%)$ & $8.23 \pm 2.81$ & $7.95 \pm 2.82$ & 0.480 \\
Thrombocytocrit $(\%)$ & $0.20 \pm 0.08$ & $0.20 \pm 0.08$ & 0.590 \\
MPV (fl) & $8.95 \pm 1.69$ & $8.73 \pm 1.33$ & 0.268 \\
PDW $(\%)$ & $16.77 \pm 1.43$ & $16.82 \pm 0.75$ & 0.727 \\
PT (second) & $12.71 \pm 0.88$ & $12.74 \pm 1.40$ & 0.839 \\
INR & $0.98 \pm 0.08$ & $0.99 \pm 0.12$ & 0.520 \\
APTT (second) & $34.58 \pm 4.56$ & $34.22 \pm 5.02$ & 0.583 \\
TT (second) & $17.19 \pm 1.41$ & $18.1 \pm 5.61$ & 0.116 \\
Fibrinogen $(\mathrm{g} / \mathrm{L})$ & $3.74 \pm 1.06$ & $3.60 \pm 0.80$ & 0.289 \\
\hline Abreviations.A/G & & & \\
\hline
\end{tabular}

Abbreviations: A/G, albumin to globulin ration; ALT, Alanine aminotransferase; AST, Aspartate aminotransferase; HDL, high-density lipoprotein; LDL, lowdensity lipoprotein; $\mathrm{HDL} / \mathrm{CHO}$, high-density lipoprotein to cholesterol ration; WBC, white blood cell; RBC, red blood cell; MPV, mean platelet volume; PDW, platelet distribution width; PT, prothrombin time; INR, international normalized ratio; APTT, activated partial thromboplastin time; $\mathrm{TT}$, thrombin time. 
Supplementary Table 4. Six patients for microarray analysis.

\begin{tabular}{lccccccccc}
\hline Patients & IVE & Age & Gender & TNM stage & LY\% & NE\% & Location & Lymph node metastasis & Histologic type \\
\hline NO.1 & YES & 61 & Male & T4aN1bM0 & 27.5 & 33.0 & Rectum & $2 / 13$ & Moderate \\
NO.2 & YES & 60 & Male & T4aN1bM0 & 24.0 & 66.7 & Sigmoid & $3 / 11$ & Moderate \\
NO.3 & YES & 62 & Male & T4aN2bM0 & 16.8 & 77.9 & Rectum & $7 / 12$ & Moderate \\
NO.4 & NO & 52 & Female & T4aN1bM0 & 32.0 & 57.0 & Rectum & $3 / 18$ & Moderate \\
NO.5 & NO & 43 & Male & T4aN2aM0 & 37.2 & 57.3 & Rectum & $6 / 11$ & Moderate \\
NO.6 & NO & 63 & Male & T4aN1aM0 & 41.0 & 42.7 & Rectum & $2 / 14$ & Moderate \\
\hline
\end{tabular}

Supplementary Table 5. Top ten up/down regulated genes in IVE group.

\begin{tabular}{lcc}
\hline Genes & $\log$ (Fold change) & $\boldsymbol{P}$-value \\
\hline CALB1 & 9.250 & 0.001 \\
REG1A & 5.930 & 0.011 \\
DSG3 & 5.928 & 0.001 \\
KLK8 & 5.866 & 0.022 \\
ABHD12B & 5.697 & 0.034 \\
XLOC_004031 & 5.419 & 0.026 \\
KLK12 & 3.993 & 0.024 \\
MAGEA6 & 3.355 & 0.031 \\
KRT16P2 & 3.105 & 0.011 \\
PLA2G4D & 3.104 & 0.010 \\
XLOC_011804 & -2.677 & 0.042 \\
RIIAD1 & -2.731 & 0.007 \\
ASPN & -2.748 & 0.014 \\
XLOC_12_015529 & -2.801 & 0.020 \\
DRD2 & -2.935 & 0.010 \\
ZBTB16 & -2.943 & 0.024 \\
XLOC_012248 & -2.945 & 0.008 \\
XLOC_12_010573 & -3.307 & 0.023 \\
PTF1A & -3.526 & 0.044 \\
DKK1 & -4.461 & 0.023 \\
\hline
\end{tabular}

